\title{
Brain Abscesses Associated with Asymptomatic Pulmonary Arteriovenous Fistulas
}

\author{
Taek-Kyun Nam, M.D., Ph.D., Yong-sook Park, M.D., Ph.D., Jeong-taik Kwon, M.D., Ph.D. \\ Department of Neurosurgery, Chung-Ang University College of Medicine, Seoul, Korea
}

Brain abscess commonly occurs secondary to an adjacent infection (mostly in the middle ear or paranasal sinuses) or due to hematogenous spread from a distant infection or trauma. Pulmonary arteriovenous fistulas (AVFs) are abnormal direct communications between the pulmonary artery and vein. We present two cases of brain abscess associated with asymptomatic pulmonary AVF. A 65-year-old woman was admitted with a headache and cognitive impairment that aggravated 10 days prior. An magnetic resonance (MR) imaging revealed a brain abscess with severe edema in the right frontal lobe. We performed a craniotomy and abscess removal. Bacteriological culture proved negative. Her chest computed tomography (CT) showed multiple AVFs. Therapeutic embolization of multiple pulmonary AVFs was performed and antibiotics were administered for 8 weeks. A 45-yearold woman presented with a 7-day history of progressive left hemiparesis. She had no remarkable past medical history or family history. On admission, blood examination showed a white blood cell count of 6290 cells/uL and a high sensitive C-reactive protein of $2.62 \mathrm{mg} / \mathrm{L}$. CT and MR imaging with MR spectroscopy revealed an enhancing lesion involving the right motor and sensory cortex with marked perilesional edema that suggested a brain abscess. A chest CT revealed a pulmonary AVF in the right upper lung. The pulmonary AVF was obliterated with embolization. There needs to consider pulmonary AVF as an etiology of cerebral abscess when routine investigations fail to detect a source.

Key Words : Arteriovenous fistula · Arteriovenous malformations · Brain abscess · Pulmonary.

\section{INTRODUCTION}

The cerebral abscess is a common central nervous system infection that can result from trauma, hematogenous spread, or spread from an adjacent infection such as otitis media or sinusitis. Despite exhaustive searches, 15 to $30 \%$ of abscesses are termed cryptogenic when no source of infection is identified $^{20)}$. A distant infection focus that can cause brain abscesses is a cardiac right to left shunt, which is related to patent foramen ovale ${ }^{15)}$, cyanotic cardiac disease ${ }^{15)}$ or pulmonary arteriovenous malformation or fistula (AVF). Pulmonary AVF is a rare congenital vascular malformation involving direct communication between the pulmonary artery and vein without an intervening capillary bed. Approximately $80-95 \%$ of pulmonary AVFs are associated with hereditary hemorrhagic telangiectasia (HHT), known as Osler-Weber-

- Received: July 14, 2015 •Revised: September 3, 2015 •Accepted: February 5, 2016

- Address for reprints : Yong-sook Park, M.D., Ph.D.

Department of Neurosurgery, Chung-Ang University Hospital, 102 Heukseok-ro, Dongjak-gu, Seoul 06973, Korea

Tel : +82-2-6299-1610, Fax : +82-2-6299-1597, E-mail : cuttage@cau.ac.kr

This is an Open Access article distributed under the terms of the Creative Commons Attribution Non-Commercial License (http://creativecommons.org/licenses/by-nc/4.0) which permits unrestricted non-commercial use, distribution, and reproduction in any medium, provided the original work is properly cited. 
Rendu syndrome ${ }^{5,8,9)}$. The clinical triads of pulmonary AVF is cyanosis, exertional dyspnea, and digital clubbing; however, $56 \%$ of one large series were asymptomatic ${ }^{8)}$. The most prominent central nervous system (CNS) complications associated with pulmonary AVFs are neurologic events, including transient ischemic attacks ${ }^{31)}$, recurrent stroke ${ }^{1,6,18,27)}$, brain abscesses, and seizures $^{26)}$. Reports of asymptomatic idiopathic pulmonary AVF-related brain abscesses are rare. We will focus on the cryptogenic brain abscess as developed by patients with idiopathic pulmonary AVF, which may be detected only if we consider it may cause the brain abscess.

\section{CASE REPORT}

\section{Case 1}

A 65-year-old woman was admitted with a 1-month history of headache and cognitive impairment that had become aggravated 10 days prior. She showed impairment in orientation and judgment, but there were no lateralization signs of motor paralysis or cranial nerve deficits. Her past medical history was unremarkable except for intermittent medication for hypercholesterolemia. There was no history of diabetes mellitus, hypertension, lung disease or heart disease. There was no sinusitis or ear infection. Her blood pressure was $110 / 70 \mathrm{mmHg}$, pulse rate was $74 / \mathrm{min}$, body temperature was $36.5^{\circ} \mathrm{C}$, and her respiration rate was 20 breaths $/ \mathrm{min}$. $\mathrm{Hb} / \mathrm{Hct}$ was $14.5 \mathrm{~g} / \mathrm{dL} / 41.6 \%$. Erythrocyte sedimentation rate was $54 \mathrm{~mm} / \mathrm{h}$ and $\mathrm{C}$-reactive protein (CRP) was 0.22 $\mathrm{mg} / \mathrm{L}$. Arterial blood gas analysis revealed a $\mathrm{pH}$ of 7.425, $\mathrm{pCO}_{2}$ of $42.5 \mathrm{mmHg}, \mathrm{pO}_{2}$ of $90.4 \mathrm{mmHg}$, and an $\mathrm{HCO}_{3}$ of $22.2 \mathrm{mmoL} / \mathrm{L}$ on room air. Total cholesterol was $249 \mathrm{mg} / \mathrm{dL}$ and LDL-cholesterol was $172 \mathrm{mg} / \mathrm{dL}$. Blood glucose was 117 $\mathrm{mg} / \mathrm{dL}$. Thyroid hormone and pulmonary function tests were all within normal range. Echocardiography showed normal global left ventricular systolic function. Brain computed tomography (CT) showed a mass with perilesional edema on the right frontal lobe. Brain magnetic resonance (MR) imaging revealed a $4 \times 3-\mathrm{cm}$ ring enhanced mass in the right frontal lobe, which was associated with severe edema and midline shifting to the left side (Fig. 1). We performed a craniotomy and abscess removal. Bacteriological culture
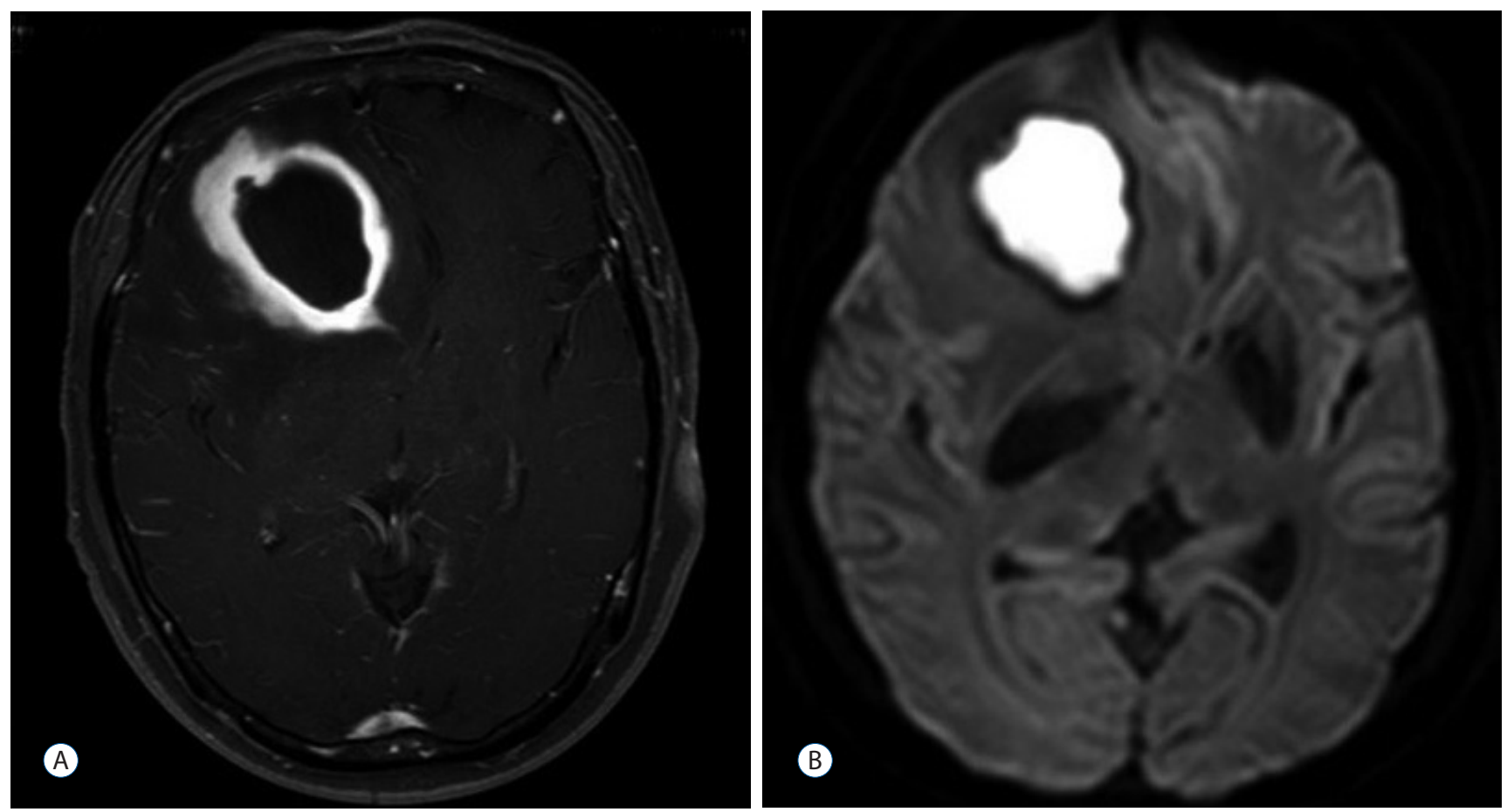

Fig. 1. Brain magnetic resonance imaging of case 1. A $4 \times 3-\mathrm{cm}$ ring-enhanced mass in the right frontal lobe, which was associated with severe edema and midline shifting to the left side (A). Diffusion restriction of the enhancing area suggests that the lesion is an abscess (B). 
proved negative. A chest $\mathrm{x}$ ray showed nodular infiltrations on the right mid-lung zone and the left upper and lower lung zones. A chest CT showed multiple pulmonary AVFs. Therapeutic embolization was performed (Fig. 2) and antibiotics were maintained for 8 weeks. Her past history gave no indication of exertional dyspnea or episodes of hemoptysis, melena, hematemesis, epistaxis or hematuria that might suggest underlying HHT.
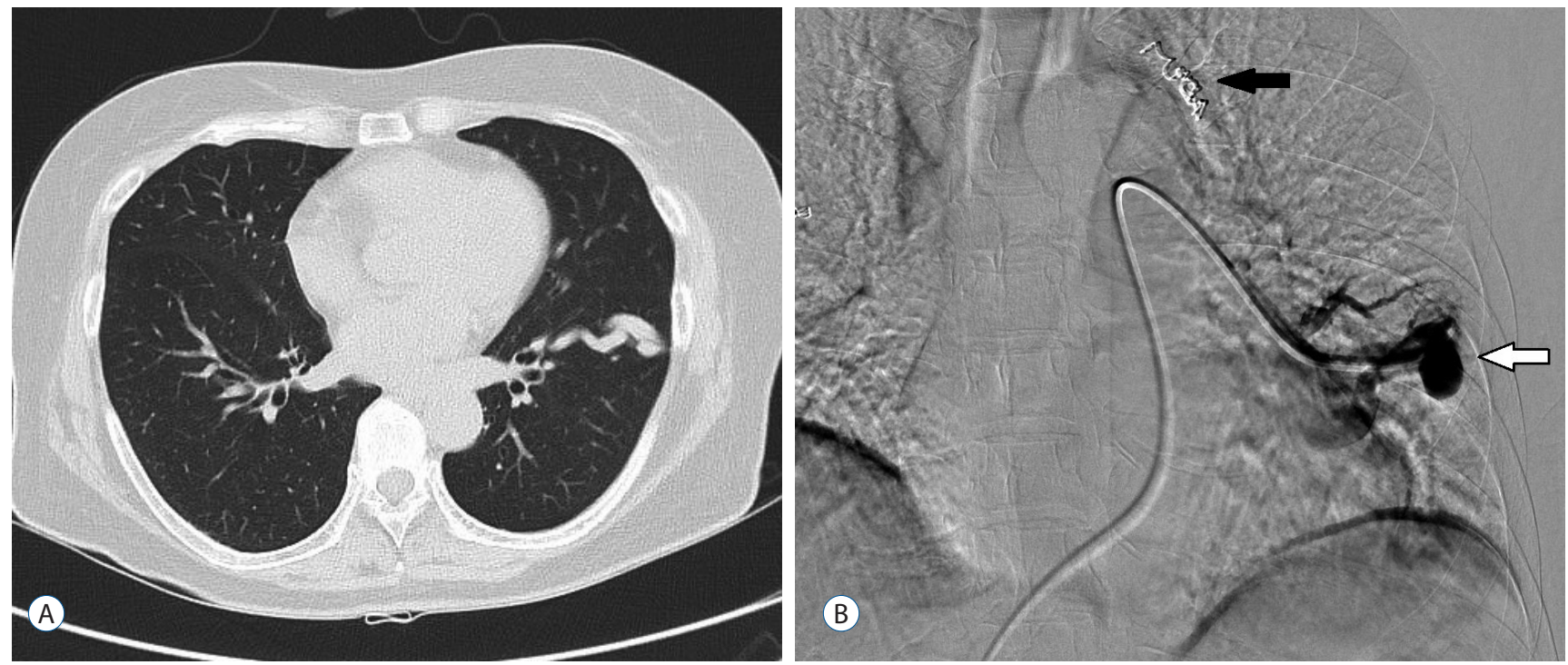

Fig. 2. Chest computed tomography (A) and angiography (B) of case 1. Fistulous vascular abnormality on the left lower lung field (A). A catheter is used to perform embolization (white arrow). Another lesion on the left upper lung field was already embolized with coils (black arrow; B).
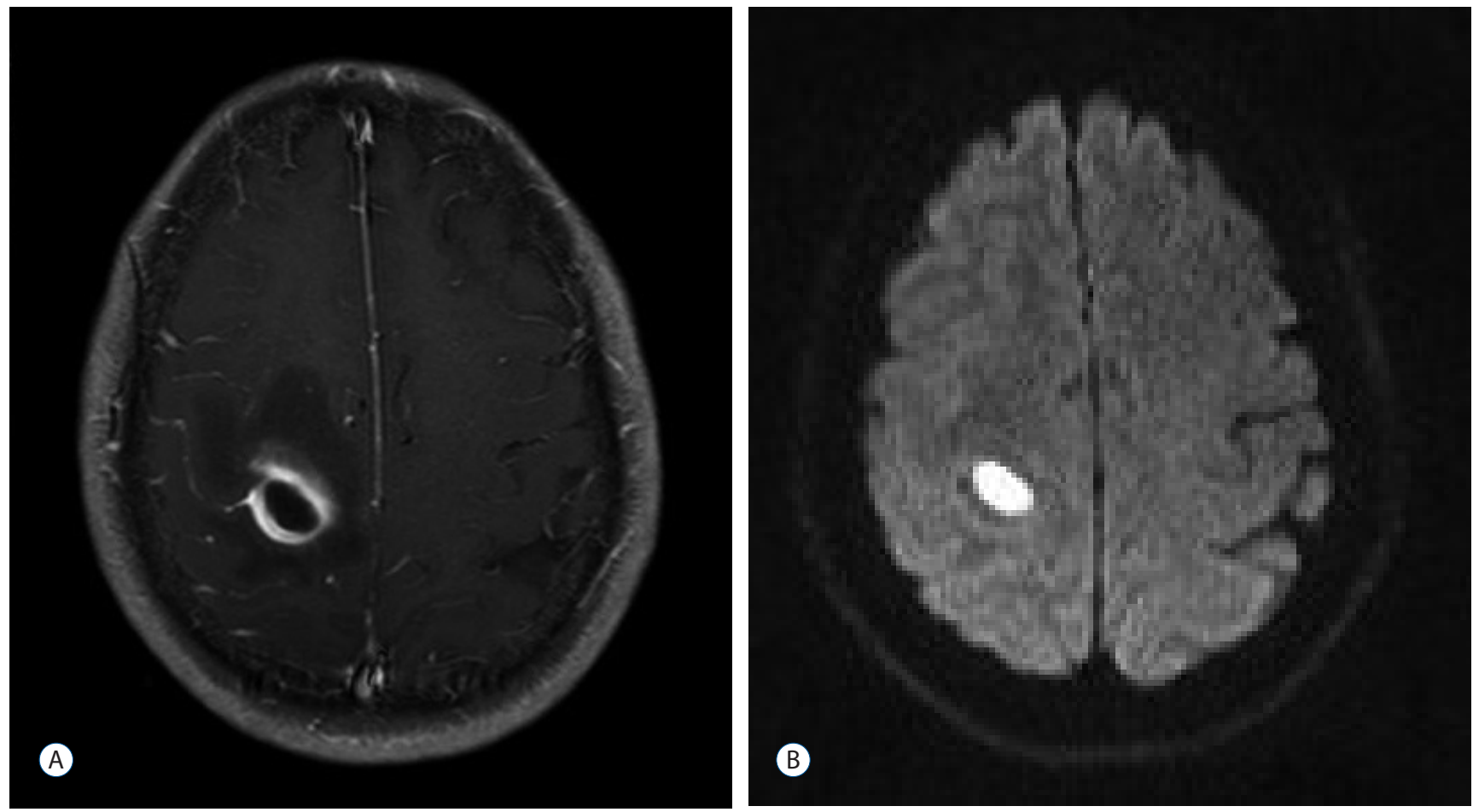

Fig. 3. A 45-year-old woman (case 2) presented with a 7-day history of a progressive left hemiparesis. Enhanced brain magnetic resonance (MR) imaging shows a well-enhancing ovoid mass on the right motor and sensory cortex measuring $1.5 \times 0.9 \mathrm{~cm}(\mathrm{~A})$. Diffusion weighted MR reveals restriction of the mass (B). 


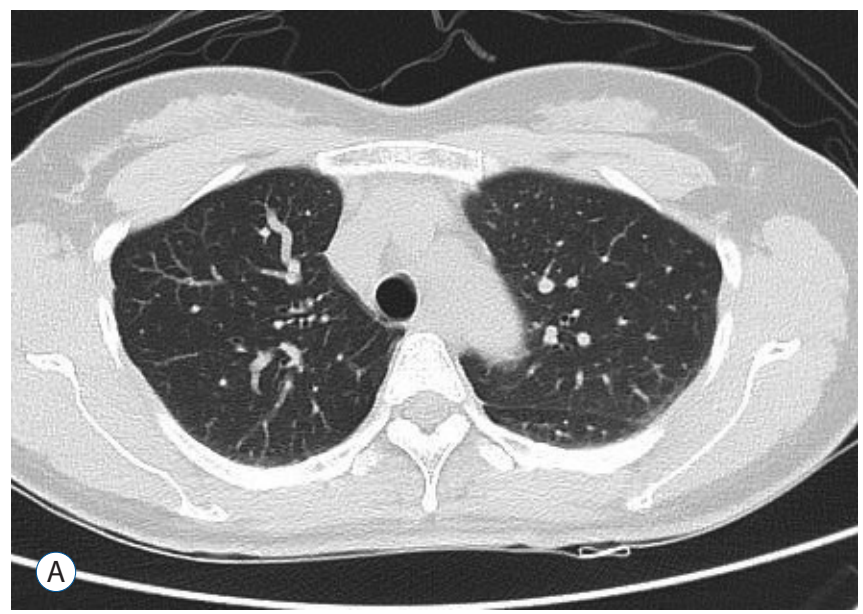

Fig. 4. Chest computed tomography (A) and angiography (B) of case 2. Fistulous dilatation of the pulmonary vasculature on the right upper lung field (A). The lesion is approached with a catheter to perform embolization. It was a single lesion (B).

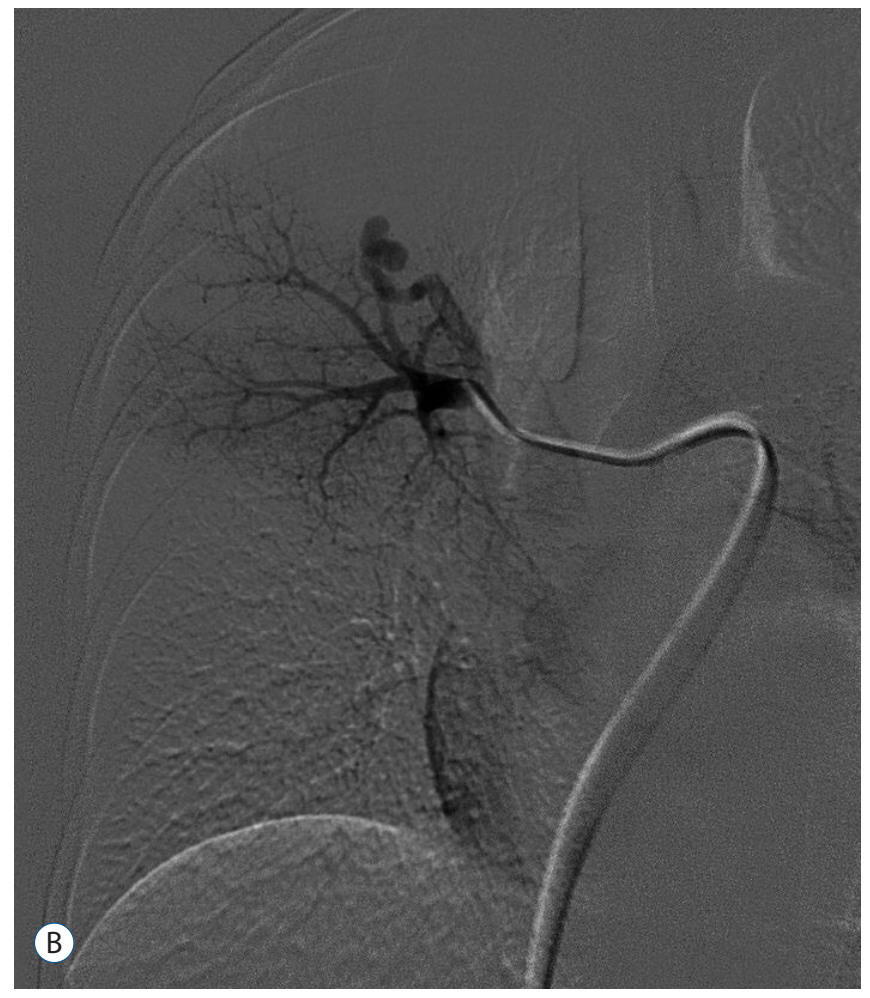

\section{Case 2}

A 45-year-old woman presented with a 7-day history of a progressive left hemiparesis. She had no remarkable past medical history or family history. On admission, blood tests showed a $\mathrm{Hb}$ of $13.4 \mathrm{~g} / \mathrm{dL}$, an Hct of $39.6 \%$, a white blood cell (WBC) count of 6290 cells/ $\mu \mathrm{L}$, and a CRP elevated to $2.62 \mathrm{mg} / \mathrm{L}$. Liver function tests were within normal range. Blood glucose was $101 \mathrm{mg} / \mathrm{dL}$. There were no systemic or focal infection signs. Diffusion MR imaging showed a diffusion-restricted ovoid mass on the right motor and sensory cortex measuring $1.5 \times 0.9 \mathrm{~cm}$ that was surrounded by diffuse vasogenic perilesional edema (Fig. 3). MR imaging and MR spectroscopy revealed an enhancing lesion involving the right motor and sensory cortex and increased lactate/ lipid complex, which was compatible with a brain abscess. A chest $\mathrm{x}$ ray did not suggest underlying lung disease. However, a chest CT revealed a pulmonary AVF in the right upper lung (Fig. 4). The brain abscess progressed despite treatment with vancomycin and ceftriaxone, so it was removed via craniotomy and the pulmonary AVF was embolized. Bacteriological culture of the pus revealed no growth. Additional

\section{DISCUSSION}

Cryptogenic brain abscesses can occur due to rare diseases that are not addressed in routine clinical practice. Congenital cyanotic heart disease $^{3)}$, patent foramen ovale ${ }^{12,15)}$, thoracic infection $^{19)}$ or asymptomatic dental infections ${ }^{7)}$ are commonly associated with cerebral abscesses. Idiopathic asymptomatic pulmonary AVFs are also a cause of brain abscess, especially recurrent brain abscess (Table 1).

The incidence of idiopathic pulmonary AVF-related CNS complications is between 19 and $59 \%{ }^{11,25,29)}$. Associated neurological events included migraine, transient ischemic attack, stroke, abscess, and seizure ${ }^{17,26,30)}$. The incidence of brain abscess in patients with a pulmonary AVF is around 1 to $5 \%{ }^{8)}$.

The most likely mechanism for these neurological events is a paradoxical embolism across the pulmonary AVF or across a coexisting cerebral arteriovenous malformation in patients with $\mathrm{HHT}^{17)}$. The pulmonary capillary bed acts as a filter 


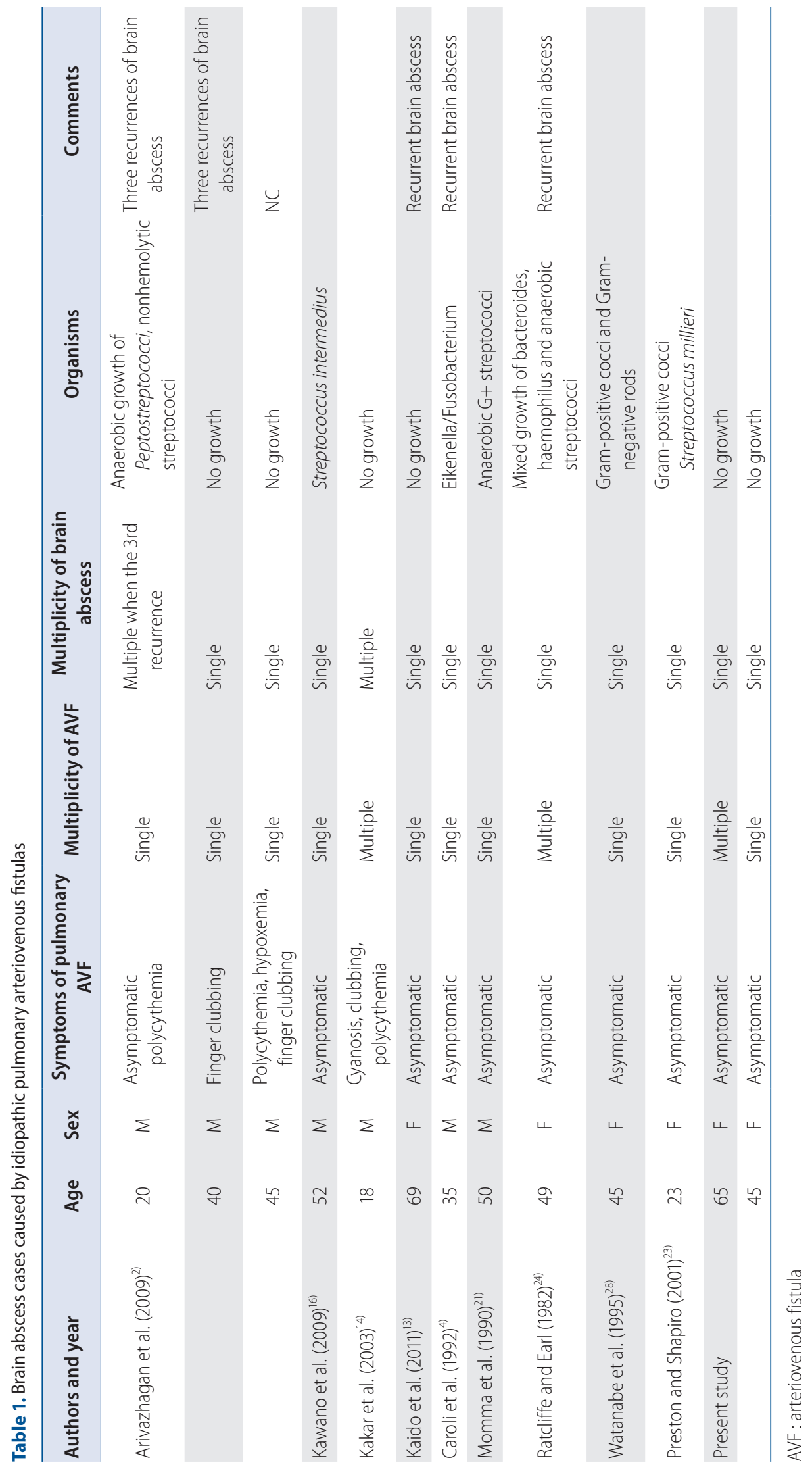


that removes small thrombi and bacteria as they enter the bloodstream, even during daily activities such as oral hygiene. In a pulmonary AVF, the pulmonary capillary bed is bypassed, providing a direct right to left shunt that depends on the diameter of the feeding artery. As a consequence, patients may develop paradoxical emboli that present as a transient ischemic attack, stroke, or brain abscess ${ }^{5}$.

The fundamental defect that we found was a right-to-left shunt from the pulmonary artery to the pulmonary vein, and the degree of shunting determines the clinical effects. If shunting is minimal, cyanotic symptoms are usually absent. If the right-to-left shunt is greater than $20 \%$ of the systemic cardiac output, or if there is reduction of hemoglobin by more than $50 \mathrm{~g} / \mathrm{L}$, the patient will have obvious cyanosis, clubbing, and polycythemia ${ }^{17}$. The characteristic findings of cyanosis, clubbing and an extra-cardiac murmur do not always accompany pulmonary AVF, and diagnosis may be difficult. Asymptomatic patients are common and account for $13 \%$ to $56 \%$ of patients ${ }^{8,9,30)}$. An absence of symptoms does not preclude diagnosis of pulmonary AVF. A review of the Mayo Clinic experience suggested a morbidity of 26$33 \%$ and mortality of $8-16 \%$ in untreated patients with pulmonary $\mathrm{AVF}^{26}$. The international guidelines for the management of pulmonary AVF in HHT recommends that treatments should be applied to all adults with AVFs and children with symptomatic pulmonary AVFs. The decision to treat in asymptomatic children (no dyspnea, no exercise intolerance, no growth delay, no cyanosis or clubbing, no previous complication) should be made on a case-by-case basis. The selection of pulmonary AVFs for embolization is based on feeding artery diameter, generally $3 \mathrm{~mm}$ or great$\mathrm{er}^{10)}$.

A literature review (Table 1) indicates that idiopathic pulmonary AVFs can cause brain abscess in patients as young as 18 years old. Based on these reported series, 10 of 13 patients did not have pulmonary AVF-related symptoms until the brain abscess developed. Five suffered recurrent brain abscesses. Idiopathic pulmonary AVFs are more frequently solitary, around $80 \%$, compared with that of HHT $(<40 \%)^{30)}$. It means idiopathic pulmonary AVFs are less like- ly to be associated with large right-to-left shunt, this might in part explain why patients with idiopathic PAVMs might have a lower frequency of cyanosis and polycythemia. Also, previous HHT series have shown an association between number of pulmonary AVFs and cerebral abscess risk ${ }^{22}$. This might explain why idiopathic pulmonary AVFs are associated with a lower frequency of cerebral abscess than in HHT.

The organisms in the brain abscess were not consistent but most frequently isolated ones were streptococci genus. 6 cases out of 13 did not reveal an organism at all.

If young adults without a premorbid history present with a brain abscess, pulmonary problems must be evaluated.

\section{CONCLUSION}

This report highlights the need to consider pulmonary AVF as an etiology of cerebral abscess when routine investigations fail to detect a source. Diagnosis can be confirmed through thoracic CT or pulmonary angiography.

\section{References}

1. Ahn KT, Choi JH, Park SW : Pulmonary arteriovenous fistula in a patient with cryptogenic stroke. Heart 97 : 2093, 2011

2. Arivazhagan A, Pandey P, Anandh B, Abraham RG, Indira DB, Sampath S, et al. : An unusual etiology of recurrent cerebral abscesses-a report of 3 cases. Surg Neurol 71 : 241-244; discussion 245, 2009

3. Berthrong M, Sabiston DC Jr : Cerebral lesions in congenital heart disease, a review of autopsies on 162 cases. Bull Johns Hopkins Hosp 89 : 384-406, 1951

4. Caroli M, Arienta C, Rampini PM, Balbi S : Recurrence of brain abscess associated with asymptomatic arteriovenous malformation of the lung. Neurochirurgia (Stuttg) 35 : 167-170, 1992

5. Cartin-Ceba R, Swanson KL, Krowka MJ : Pulmonary arteriovenous malformations. Chest 144 : 1033-1044, 2013

6. Chessa M, Drago M, Krantunkov P, Bini MR, Butera G, De Rosa G, et al. : Differential diagnosis between patent foramen ovale and pulmonary arteriovenous fistula in two patients with previous cryptogenic stroke caused by presumed paradoxical embolism. J Am Soc Echocardiogr $15: 845-846,2002$ 
7. Corson MA, Postlethwaite KP, Seymour RA : Are dental infections a cause of brain abscess? Case report and review of the literature. Oral Dis 7 : 61-65, 2001

8. Dines DE, Arms RA, Bernatz PE, Gomes MR : Pulmonary arteriovenous fistulas. Mayo Clin Proc 49 : 460-465, 1974

9. Dines DE, Seward JB, Bernatz PE : Pulmonary arteriovenous fistulas. Mayo Clin Proc 58 : 176-181, 1983

10. Faughnan ME, Palda VA, Garcia-Tsao G, Geisthoff UW, McDonald J, Proctor $\mathrm{DD}$, et al. : International guidelines for the diagnosis and management of hereditary haemorrhagic telangiectasia. J Med Genet 48 : 73-87, 2011

11. Hodgson $\mathrm{CH}$, Kaye RL : Pulmonary arteriovenous fistula and hereditary hemorrhagic telangiectasia: a review and report of 35 cases of fistula. Dis Chest 43 : 449-455, 1963

12. Horiuchi Y, Kato Y, Dembo T, Takeda H, Fukuoka T, Tanahashi N : Patent foramen ovale as a risk factor for cryptogenic brain abscess: case report and review of the literature. Intern Med 51 : 1111-1114, 2012

13. Kaido T, Moriyama Y, Ueda K, Higashiura W, Sakaguchi H, Kichikawa K : Recurrent brain abscess induced by pulmonary arteriovenous fistula. $J$ Infect Chemother 17 : 552-554, 2011

14. Kakar A, Byotra SP, Gupta A, Jain N : Pulmonary arteriovenous fistula presenting as multiple brain abscess. J Assoc Physicians India 51 : 626-628, 2003

15. Kawamata T, Takeshita M, Ishizuka N, Hori T : Patent foramen ovale as a possible risk factor for cryptogenic brain abscess: report of two cases. Neurosurgery 49 : 204-206; discussion 206-207, 2001

16. Kawano H, Hirano T, Ikeno K, Fuwa I, Uchino M : Brain abscess caused by pulmonary arteriovenous fistulas without Rendu-Osler-Weber disease. Intern Med 48 : 485-487, 2009

17. Khurshid I, Downie GH: Pulmonary arteriovenous malformation. Postgrad Med J 78 : 191-197, 2002

18. Kimura K, Minematsu K, Nakajima M : Isolated pulmonary arteriovenous fistula without Rendu-Osler-Weber disease as a cause of cryptogenic stroke. J Neurol Neurosurg Psychiatry 75 : 311-313, 2004

19. Lutz TW, Landolt $H$, Wasner M, Gratzl 0 : Diagnosis and management of abscesses in the basal ganglia and thalamus: a survey. Acta Neuro- chir (Wien) $127: 91-98,1994$

20. Mathisen GE, Johnson JP : Brain abscess. Clin Infect Dis 25 : 763-779; quiz 780-781, 1997

21. Momma F, Ohara S, Ohyama T, Moto A, Okada H, Harada H : Brain abscess associated with congenital pulmonary arteriovenous fistula. Surg Neurol 34 : 439-441, 1990

22. Moussouttas M, Fayad P, Rosenblatt M, Hashimoto M, Pollak J, Henderson $\mathrm{K}$, et al. : Pulmonary arteriovenous malformations: cerebral ischemia and neurologic manifestations. Neurology 55 : 959-964, 2000

23. Preston DC, Shapiro BE : Pulmonary arteriovenous fistula and brain abscess. Neurology $56: 418,2001$

24. Ratcliffe PJ, Earl CJ : Recurrent cerebral abscess in association with pulmonary arteriovenous fistulae. J Neurol Neurosurg Psychiatry 45 : 566-567, 1982

25. Sluiter-Eringa $H$, Orie NG, Sluiter $H J$ : Pulmonary arteriovenous fistula. Diagnosis and prognosis in noncomplainant patients. Am Rev Respir Dis 100 : 177-188, 1969

26. Swanson KL, Prakash UB, Stanson AW : Pulmonary arteriovenous fistulas: Mayo Clinic experience, 1982-1997. Mayo Clin Proc 74 : 671-680, 1999

27. Todo K, Moriwaki H, Higashi M, Kimura K, Naritomi H : A small pulmonary arteriovenous malformation as a cause of recurrent brain embolism.

AJNR Am J Neuroradiol 25 : 428-430, 2004

28. Watanabe N, Munakata Y, Ogiwara M, Miyatake M, Nakagawa F, Hirayama $\mathrm{J}$ : A case of pulmonary arteriovenous malformation in a patient with brain abscess successfully treated with video-assisted thoracoscopic resection. Chest 108 : 1724-1727, 1995

29. White RI Jr, Lynch-Nyhan A, Terry P, Buescher PC, Farmlett EJ, Charnas $L$, et al. : Pulmonary arteriovenous malformations: techniques and longterm outcome of embolotherapy. Radiology 169 : 663-669, 1988

30. Wong HH, Chan RP, Klatt R, Faughnan ME : Idiopathic pulmonary arteriovenous malformations: clinical and imaging characteristics. Eur Respir J 38 : 368-375, 2011

31. Yamakuchi M, Tanaka S, Tomosugi T, Moroki K, Yamada M, Toujou H, et al. : Pulmonary arteriovenous fistula manifesting as amaurosis fugax-case report. Neurol Med Chir (Tokyo) 40 : 264-267, 2000 